\title{
The Knowledge Society: a manifesto for knowledge and learning
}

\author{
Miltiadis D. Lytras*
}

ELTRUN, The Research Center

Department of Management Science and Technology

Athens University of Economics and Business

47A Evelpidon Str and 33 Lefkados Str, GR-113 62 Athens, Greece

Computer Engineering and Informatics Department

University of Patras and

Research Academic Computer Technology Institute

61 Riga Feraiou Street, 26221 Patras, Greece

E-mail:mdl@eltrun.gr E-mail: Lytras@ceid.upatras.gr

*Corresponding author

\section{Miguel Angel Sicilia}

Computer Science Department, University of Alcalá

Ctra. Barcelona, km. 33.6 - 28871 Alcalá de Henares (Madrid), Spain

E-mail:msicilia@uah.es

\begin{abstract}
The Knowledge Society is the new context of our living and working. Towards this milestone, the International Journal of Knowledge and Learning reveals a scientific debate where academics, practitioners, researchers, policy makers, as well as government bodies, industry and nonprofit organisations provide their understanding for the integrated character of knowledge and learning. In this position document, we comment on the nature of Knowledge Society and we develop a 'Roadmap' for our future discussions and contributions.
\end{abstract}

Keywords: knowledge; learning; Knowledge Society.

Reference to this paper should be made as follows: Lytras, M.D. and Sicilia, M.A. (2005) 'The Knowledge Society: a manifesto for knowledge and learning', Int. J. Knowledge and Learning, Vol. 1, Nos. 1/2, pp.1-11.

Biographical notes: Miltiadis D. Lytras obtained his PhD from the Athens University of Economics and Business-AUEB. He is the Editor-in-Chief of IJKL. He is a Faculty Member in the Computer Engineering and Informatics Department-CEID (University of Patras), Department of Business Administration-BMA (University of Patras), in the Technology Education and Digital Systems Department-TED (University of Piraeus) and in the International MBA program of AUEB (www.i-mba.aueb.gr). Since 1998, he is a Research Officer in ELTRUN, the Research Center in the Department of Management Science and Technology at the Athens University of Economics and Business. His research focuses on semantic web, knowledge management and e-learning, with more than 50 publications in these areas. $\mathrm{He}$ has co-edited nine special issues in international journals and has authored and edited six books, He is the founder of the Semantic Web and Information Systems Special Interest Group in the Association for Information Systems (www.sigsemis.org) and served as the Editor-in-Chief of three international journals while he is Associate Editor or Editorial Board Member in five more. 
Miguel A. Sicilia obtained his degree in Computer Science from the Pontifical University of Salamanca, Madrid, Spain, in 1996 and his PhD from Carlos III University in 1999. From 1997 to 1999 he worked as an Assistant Professor and later as a part-time lecturer at the Computer Science Department of the same university. He also worked as a Software Architect in e-commerce consulting firms. From 2002 to 2003, he worked as a full-time lecturer at Carlos III University, after which he joined the University of Alcalá. His research interests are primarily in the areas of adaptive hypermedia, learning technology, and human-computer interaction, with a special focus on the role of uncertainty and imprecision handling techniques in those fields.

\section{Introduction: knowledge and learning: main ontological considerations}

In the 21st century, several scientific debates have emerged. Irrespective of the philosophical origins or disciplinary lenses, one major converging point of all the argumentations is that knowledge and learning are the 'new' battlefields for the evolution of our society and mankind. The so-called Knowledge Society summarises a number of unsolved issues, blurred perceptions, and potential benefits; or even an envisioned situation where the social character of knowledge and learning are exploited to their full potential for the common wealth.

From the perspective of $I J K L$, the Knowledge Society is not a new verbalism. We aim at dealing with all its aspects, and we concentrate on a balanced mix of theoretical propositions and applied technologies that provide the required knowledge highways and expand the knowledge channels for both 'providers' and 'users' of knowledge and learning. In this new journal, knowledge and learning are considered as an integrated whole where the analysis of the two parts is not limited to a philosophical discussion. Our emphasis on emerging technologies and leading edge research findings provides the unique value proposition of the new journal.

In this section, we will try to discuss in more detail the key themes in our research agenda towards the Knowledge Society.

In the past, several schools of thought have contributed with philosophical debates on the nature of knowledge and learning. Moreover different disciplines have contributed to the continuous debate on knowledge and learning performance. Figure 1 depicts the main research topics intended to be addressed by IJKL. They are the result of several ontological considerations and perceptions for knowledge and learning elaborated from recent literature. 
Figure 1 Knowledge and learning key pillars

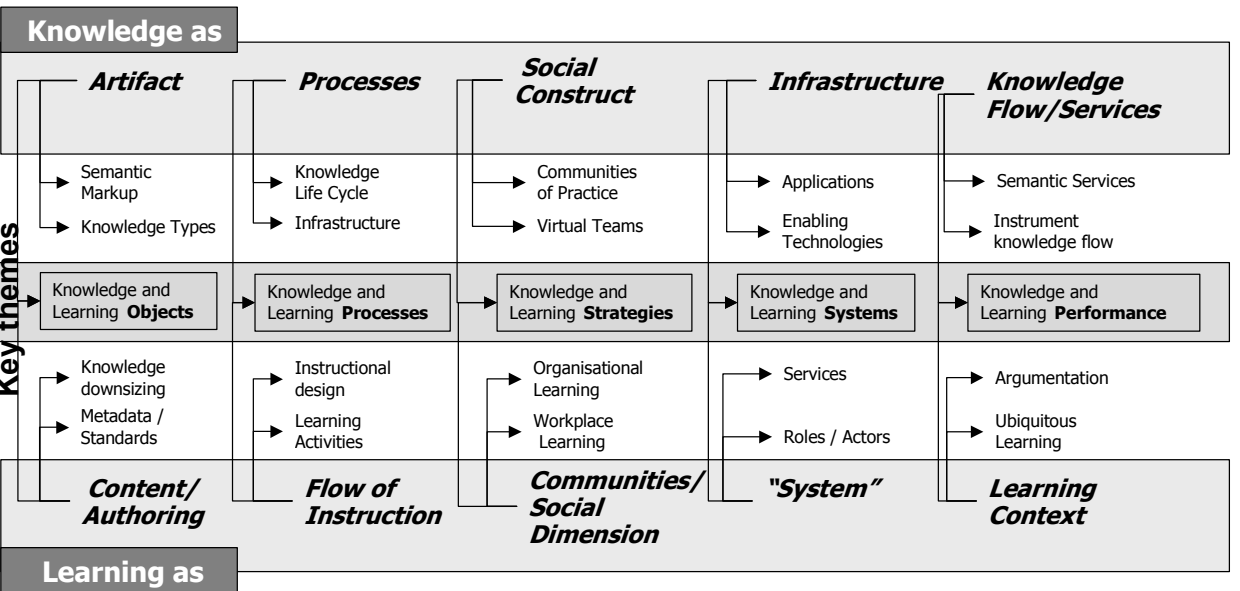

The convergence of the various themes can be summarised in five critical pillars that are described as follows.

\section{Knowledge and learning objects}

This pillar refers to the artifact perception of knowledge and to the learning content dimension of learning. The discussion of various knowledge types and the semantic annotation of knowledge are only two of the several themes that can be positioned in this pillar. The process of knowledge downsizing to reusable learning 'objects' and the justification of metadata and semantic approaches promote new ways for knowledge and learning content packaging. The new paradigm of objects is the basis for the development of value adding services for knowledge sharing and exploitation.

\section{Knowledge and learning processes}

Literature on knowledge processes, frameworks and life cycle models of knowledge reveals several critical themes towards the development of infrastructures that support the supply and the demand side of knowledge. From the other part this process-oriented approach is evident also in learning: The flow of instruction has to be based on well-defined learning activities embedded in the instructional design approach of every learning system.

\section{Knowledge and learning strategies}

The third pillar is extremely important for knowledge and learning management. Knowledge and learning strategies define the objectives and set the priorities as well as the measures for the knowledge and learning implementation. The specification of the context at this level reveals strategies at the artifact, individual, team, organisation, inter-organisational network as well as at the virtual context, the web and the semantic web. This variety of 'contexts' has also to be considered in integrative views. 


\section{Knowledge and learning systems}

Emerging technologies provide new opportunities for new applications, services, and tools. Knowledge and learning systems have a socio-technical character, which requires an extensive analysis of relevant issues. Semantic Web, Mobile and wireless applications, peer-to-peer networks, pervasive, and ubiquitous computing set a new stream of extremely interesting approaches towards more effective and dynamic knowledge and learning systems.

\section{Knowledge and learning performance}

The issue of performance relates directly to control mechanisms, standards and measures. Knowledge and learning performance measurement requires an extensive justification of metrics capable of summarising behavioural and social oriented characteristics. This objective is more complex when the analysis of performance is taking place in the context of individuals, organisation, or network.

The previous reference outlines the key objective for IJKL: Objects, Processes, Strategies, Systems, and Performance of knowledge and learning are in the centre of our interest and provide the basic backbone for the development of the Knowledge Society.

\section{The backbone and the constructs of the Knowledge Society}

The Knowledge Society has to be declared in terms of entities and relationships that integrate towards objectives related to knowledge performance. A first approach is that the Knowledge Society is being constructed upon the synergies of individuals, teams, organisations, social networks, and communities that exploit in effective ways knowledge and learning flows. This basic definition implies two abstractions that require extensive discussion. The first one relates with the backbone of the Knowledge Society.

In Figure 2 we emphasise on four dimensions while several others can be also presented. In our definition:

"Knowledge Society is a new Strategic Position of our Society where the Social and the Economic Perspective is concentrated on the exploitation of emerging technologies, and well-defined knowledge and learning infrastructures are the main vehicles for the implementation of knowledge and learning strategies. The final milestone is a society with access to knowledge and learning for everyone".

The government role towards the vision of the Knowledge Society is critical, and must be specified in strategies, policies and actions. 
Figure 2 Backbone of the Knowledge Society

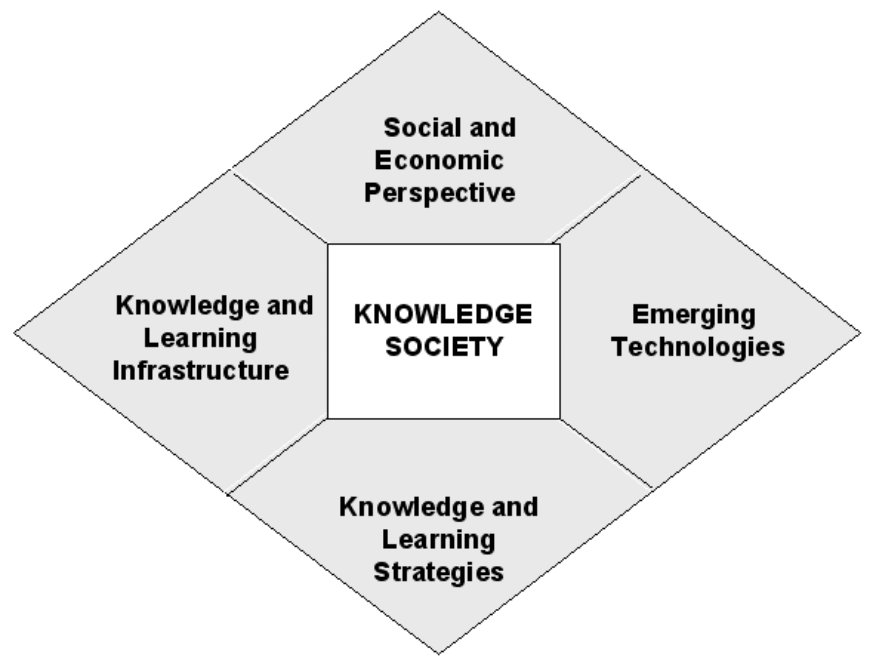

The second abstraction that influences our discussion on Knowledge Society relates to its social character. We have to define the entities that provide the constitutional parts of the knowledge society. In Figure 3, we provide a three level approach: Three entities, namely the individual, the team and the organisation, are recognised as the key elements of the social construct of knowledge society.

Figure 3 Basic construct of the Knowledge Society

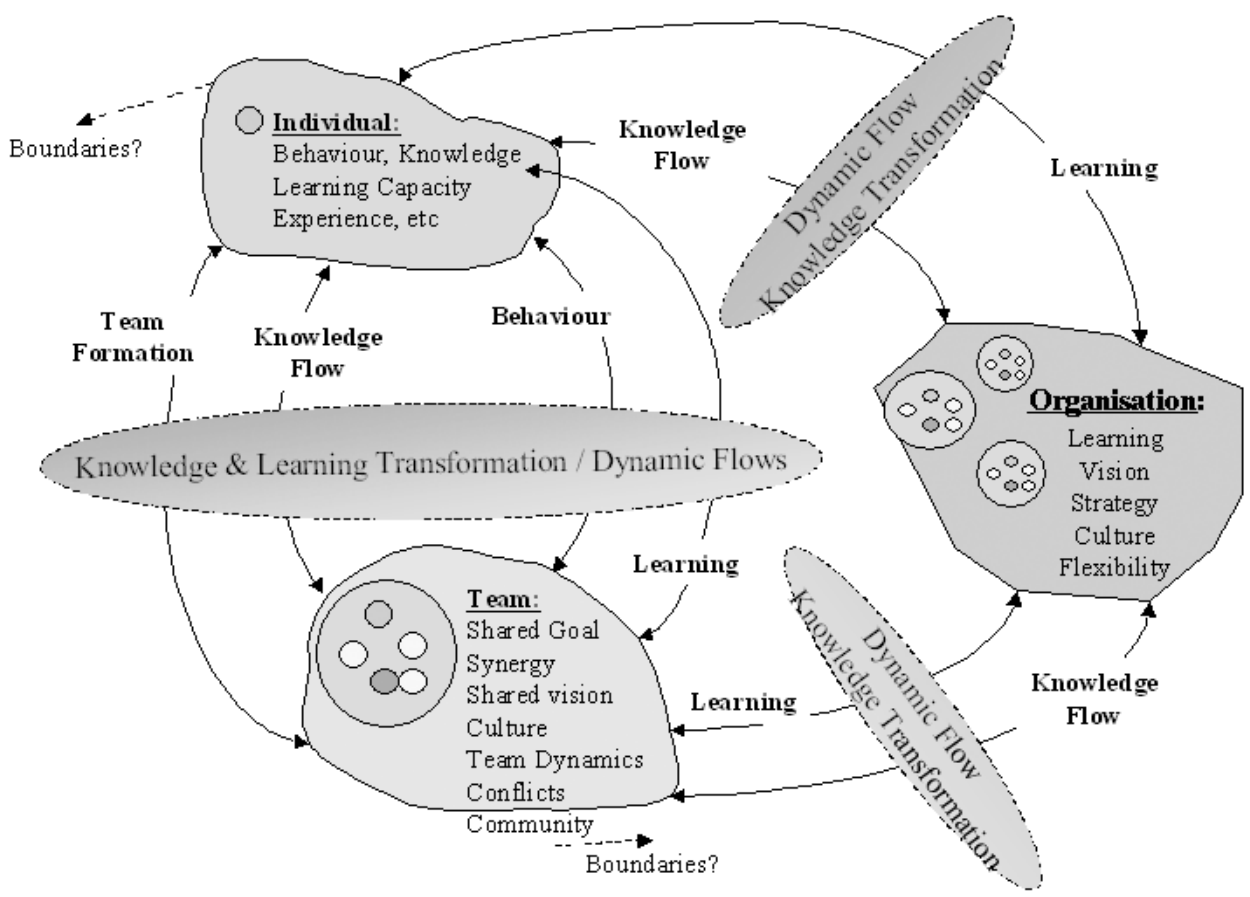


The dynamic flows between these two entities are rarely explicit in nature. The individual and team dynamics formulate a contextual environment where information technology is used to facilitate the value exchanges. Four kinds of dynamic flows are depicted: Team Formation, Knowledge Flow, Behavioural Change, and Learning. These 'flows' are knowledge transformation mechanisms. The knowledge capacity of each person is in a continuing exchange with the environment of the individual, which can be the team or the organisation.

The Knowledge Flow relates to the characteristic of humans to constitute teams that share a common objective and thus facilitate the exchange of knowledge. In this context, the critical question is the nature of knowledge. To this end, a number of knowledge category models (McAdam and McCreedy, 1999) have been proposed. A number of characteristics of knowledge have been distinguished providing the dimensions for categorisation. The traditional approach seems to be the selection of two characteristics and the justification of a two-dimensional matrix where the specified kinds of knowledge are presented. Such abstraction is easily understandable but is perhaps simplistic. In the literature, a number of knowledge category models can be identified. Boisot's model (1987) recognises two critical characteristics of knowledge: diffusion and codification. Proprietary, Personal, and Public Knowledge as well as common sense are the four suggested types of knowledge. The person in its daily practice refers to this knowledge and acts according to specific context. Hahn and Subramani (2000) provide a very interesting approach that investigates a framework of Knowledge Management Systems using two basic dimensions: The locus of knowledge and the level of the a-priori structure. These two dimensions determine the boundaries for four quadrants, where several applications are positioned in order to support knowledge management. In each quadrant, specific knowledge types are determined, thus providing an overview of knowledge types that require specific support through Information and Communication Technologies (ICTs). Nonaka et al. (Nonaka, 1994; Nonaka and Takeuchi, 1995) promote the well-known distinction of tacit and explicit knowledge, which seems to be a manifestation in knowledge management, since in its simplistic categorisation describes the admission of hidden and revealed knowledge.

The Learning Flow corresponds to the archetype of human behaviour that action and feedback promote understanding and adoption to the environment. The contextual character of learning is of critical importance. Individuals, teams and organisations have a learning capacity, which is not simply a cumulative result of individual contributions. A number of theories concerning learning have been identified for every context mentioned earlier. In an organisational context Argyris (Argyris, 1976; Argyris and Schön, 1978; Argyris, 1991; Argyris, 1993), proposes a double loop learning theory, which pertains to learning to change underlying values and assumptions. Double loop theory is based on a 'theory of action' perspective outlined by Argyris and Schon (1974) and examines reality from the point of view of human beings as actors. Changes in values, behaviour, leadership, and helping others, are all part of, and informed by, the actors' theory of action. An important aspect of the theory is the distinction between an individual's espoused theory and their 'theory-in-use' (what they actually do); bringing these two into congruence is a primary concern of double loop learning. Typically, interaction with others is necessary to identify the conflict.

At the individual level many learning theories investigate the phenomenon of learning. Two interesting approaches are provided by Bloom and Krathwohl (1984) and Shuell (1992). Bloom's Taxonomy of Educational Goals and the concept of learning 
function describe the concept of educational objectives while Shuell promotes a value carrier. Lytras et al. (2002a) through an integration of educational goals and learning functions, propose nine learning processes that potentially set the context of learning.

At the team level, a number of theories analyse the role of the group as a learning facilitator. Action learning (Watkins and Marsick, 1993) (ARL-Inquiry, 1996) can be defined as a process in which a group of people comes together more or less regularly to help each other to learn from their experience. Cooperative learning (Bossert, 1988), (Kagan, 1992) is a generic term for various small group interactive instructional procedures.

The Team Formation is one more dynamic flow, which needs further investigation that goes beyond the scope of this paper. The coherence of the team requires flows that prove to the members the value of the integration. Bird (1989) and Hackman (1990) have identified five parameters that promote the effectiveness of a team. These are vision, values, processes, structure and perceived business performance.

Finally Behavioural Change (Bandura, 1977) enlightens the way in which individuals transform their behaviour according to feedback they gain from participation in bigger social constructions. According to the behaviourists, learning can be defined as the relatively permanent change in behaviour as a result of experience or practice. In fact, the term 'learning theory' is often associated with the behavioural view. The focus of the behavioural approach is on how the environment impacts overt behaviour. The psychomotor domain is associated with overt behaviour when writing instructional objectives. In the behavioural approach, we assume that the mind is a 'black box' that we cannot see into. According to most behaviourists, the only way we know what is going on in the mind is to look at overt behaviour. The feedback loop that connects overt behaviour to stimuli that activate the senses has to be studied extensively.

The previous analysis sets a context through the admission that some patterns of relationships contextually describe knowledge transformations without taking into account the socio-technical nature of the phenomenon. In other words the relevance of knowledge and learning applications to support these relationships is something that needs justification. If we expand the basic construct by adding the inter-organisation and the society level, then a richer picture of relationships is revealed.

\section{A roadmap and an open research agenda towards the knowledge society}

The International Journal of Knowledge and Learning has a clear strategy: To provide a publication outlet where authors will share their innovative ideas with a 'thirsty' research community for new knowledge on the relevant themes. Towards this key objective, we have decided to announce very shortly special issues according to the five pillars that we presented in Section 1. Knowledge and Learning Objects, Processes, Strategies, Systems and Performance will be the key themes in forthcoming issues of IJKL aiming to provide a deep understanding of the research problems associated with these topics as well as solutions and directions justified by new approaches.

In Figure 4 we put together both our open research agenda and four critical milestones in our roadmap for the contribution of IJKL. 
Figure 4 Our roadmap and open research agenda

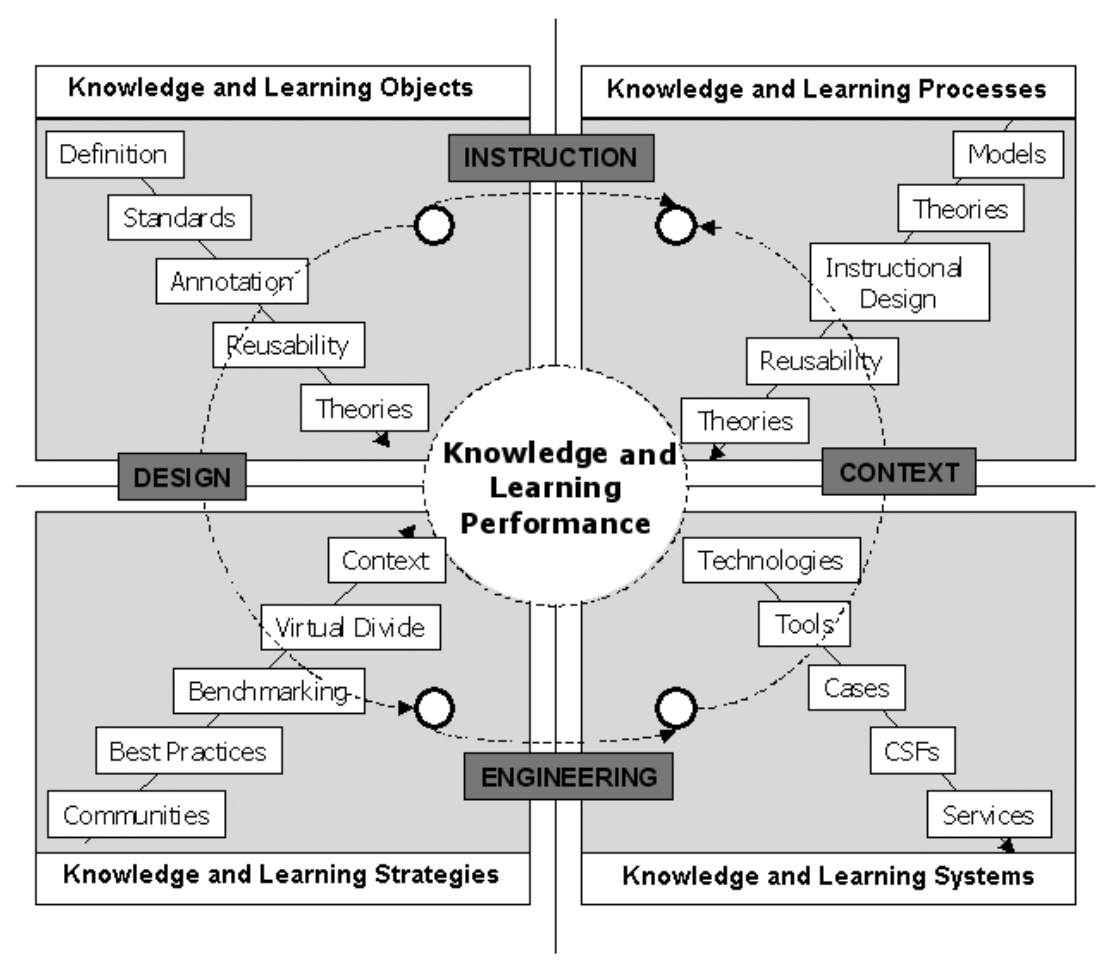

In a way this abstraction provides our microlevel towards the knowledge society. The extensive discussion of the relevant topics will be a major task in our publication strategy. In an alternative view our socio-technical orientation is pursuing four interconnected milestones, described in what follows.

\section{Design}

This milestone relates to the need in Knowledge Society to define, organise and exploit the codification of knowledge and learning artifacts in traditional form (artifact-explicit, codified) as well in emerging forms (multimedia content, virtual collaborations, argumentation, etc.). Knowledge and learning objects and strategies converge in the specification of design patterns as well as methodologies that foster industry-specific or sector-oriented knowledge and learning exploitation.

\section{Instruction}

In general, this milestone refers to the need of creating and supporting all the required processes for the flow of knowledge and learning. The convergence of Objects and Processes has to be based on an extensive modelling and also on a multidisciplinary analysis of factors influencing the exploitation of knowledge and learning. 


\section{Context}

It brings together Systems and processes perspectives on knowledge and learning. Context is the key term for knowledge society. The provision of services for citizens as well as the establishment of ubiquitous provision of knowledge and learning must be fitted in specific contexts. The inherent social character of context is mixed with the critical technical character of systems and this joint venture reveals several challenging research issues.

\section{Engineering}

Knowledge Society without enormous effort on engineering seems like a huge verbalism. Engineering as a milestone in our roadmap is exploiting all the emerging technologies for the implementation of several strategies.

\section{Conclusion}

In this short position document, we tried to sketch the positioning of IJKL. Several interesting research themes that potentially could be forthcoming special issue topics have been described. As already mentioned in the two forthcoming years, half of the issues are planned to be special issues in accordance to the five key areas discussed above.

\section{Acknowledgment}

The authors would like to acknowledge the valuable contribution and support of a number of individuals for their collaborative effort to bring this issue to completion most especially Dr. Mohammed Dorgham of Inderscience Publishers. The authors also wish to extend their thanks to Jim Corlett, Janet Marr, Sue O'Mara, Maribeth E. Siguenza, Marjorie C. Celis, and all the personnel of Inderscience and Asiatype for the dedicated effort and high-quality assistance they gave to this endeavour.

The authors would also like to express their deepest appreciation and respect to all the renowned academics and practitioners who joined the Editorial Board and who actively participated in every decision towards the overall objective to provide a high quality journal.

The authors are also grateful to all the Editors-in-Chief of the Indersience Journals that consist the Unique Profile on Knowledge and Learning and more specifically the Editors-in-Chief of International Journal of Continuing Engineering Education and Lifelong Learning, International Journal of Innovation and Learning, International Journal of Knowledge Management Studies, International Journal of Learning and Change, International Journal of Learning and Intellectual Capital, International Journal of Learning Technology and International Journal of Web Based Communities, for their collaboration towards the exploitation of the humanity's collective learning and knowledge capacity.

Dr. Sicilia would like to thank his parents, his wife Elena and two little Miguelitos for their patience and support in the long hours of working. 
Finally, Dr. Lytras would like to express his gratitude to his parents, wife Theodora, and little children Dimitris and Haroula for the joy they bring and the support they give to all his endeavours.

\section{References}

Argyris, C. (1976) Increasing Leadership Effectiveness, New York: Wiley.

Argyris, C. (1991) 'Teaching smart people how to learn', Harvard Business Review, May-June.

Argyris, C. (1993) On Organizational Learning, Cambridge, MA: Blackwell.

Argyris, C. and Schon, D. (1974). Theory in Practice, San Francisco: Jossey-Bass.

Argyris, C. and Schön, D.A. (1978) Organizational Learning: A Theory of Action Perspective, Reading, MA: Addison-Wesley.

ARL-Inquiry (1996) 'Developing an infrastructure for individual and organizational change: transfer of learning from an action reflection learning program', in E. Holton, III (Ed.) Academy of Human Resource Development 1996 Conference Proceedings, Austin, TX: Academy of HRD, pp.41-48.

Bandura, A. (1977) 'Self-efficacy: toward a unifying theory of behavioral change', Psychological Review, Vol. 84, pp.191-215.

Bird, B.J. (1989) Entrepreneurial Behaviour, Glenview, IL: Scott Foresman and Co.

Bloom, B. and Krathwohl, D. (1984) Taxonomy of Educational Objectives, Handbook I: Cognitive Domain, New York: Addison-Wesley and Co.

Boisot, M. (1987) Information and Organizations: The Manager as Anthropologist, London: Fontana/Collins.

Bossert, S.T. (1988) 'Cooperative activities in the classroom', Review of Educational Research, Vol. 15, pp.225-250.

Hackman, J.R. (1990) Groups that Work and Groups that Don't, San Fransico: Jossey-Bass, pp.1-35,479-504.

Hahn, J. and Subramani, M. (2000) 'A framework of knowledge management systems: issues and challenges for theory and practice', 21st Annual International Conference on Information Systems, ICIS 2000, Brisbane, Australia, December 10-13, pp.302-312.

Kagan, S. (1992) Cooperative Learning, 2nd edition, San Juan Capistrano, CA: Resources for Teachers.

Lytras, M.D., Pouloudi, N. and Poulymenakou, A. (2002a) 'Dynamic e-learning settings through advanced semantics. The value justification of a knowledge management oriented metadata schema', International Journal on E-Learning, Vol. 1, No. 4, pp.49-61.

McAdam, R. and McCreedy, S. (1999) 'A critical review of knowledge management models', The Learning Organization: An International Journal, Vol. 6, No. 3, pp.91-101.

Nonaka, I. (1994) 'A dynamic theory of organizational knowledge creation', Organization Science, Vol. 5, No. 1, pp.14-37.

Nonaka, I. and Takeuchi, H. (1995) The Knowledge-Creating Company: How Japanese Companies Create the Dynamics of Innovation, New York: Oxford University Press.

Shuell, T.J. (1992) 'Designing instructional computing systems for meaningful learning', in M. Jones and P.H. Winne (Eds.) Adaptive Learning Environments: Foundations and Frontiers, New York: Springer-Verlag, pp.19-54.

Watkins, K.E. and Marsick, V.J. (1993) Sculpting the Learning Organization: Lesson in the Art and Science of Systemic Change, San Francisco: Jossey-Bass. 


\section{Bibliography}

Koehn, O. and Abecker, A. (1997) 'Corporate memories for knowledge management in industrial practice: prospects and challenges', Journal of Universal Computer Science, Vol. 3, No. 8, pp.929-954.

Lytras, M.D., Pouloudi, N. and Poulymenakou, A. (2002b) 'Knowledge management convergence: expanding learning frontiers', Journal of Knowledge Management, Vol. 6, No. 1, pp.40-51.

Lytras, M.D., Themistocleous, M. and Tsilira, A. (2003a) 'A technology classification framework for e-learning purposes from a knowledge management perspective', Proceedings of Ninth Americas Conference on Information Systems, (AMCIS 2003), Association for Information Systems, pp.2573-2582.

Lytras, M.D., Themistocleous, M. and Tsilira, A. (2003b) 'Towards the semantic e-learning: an ontological oriented discussion of the new research agenda within the e-learning field', Proceedings of Ninth Americas Conference on Information Systems, (AMCIS 2003), Association for Information Systems, pp.2985-2997.

Nissen, M., Kamel, M. and Sengupta, K. (2000) 'Integrated analysis and design of knowledge systems and processes', Information Resources Management Journal, January-March, Vol. 13, No. 1, pp.24-43.

The Theory Into Practice Database, http://tip.psychology.org 